\title{
Controlar as vidas na Monarquia Católica: uma análise histórica da autobiografia de Jerónimo de Pasamonte e do Pasamonte de Cervantes
}

\section{Erick Caixeta Carvalho*}

DOI: 10.11606/issn.2318-8855.v10i1p457-483

Resumo: O presente artigo tem por objetivo principal analisar a obra autobiográfica Vida y trabajos de Jerónimo de Pasamonte, escrita pelo soldado aragonês Jerónimo de Pasamonte e concluída em 1605, buscando enfatizar aspectos desta que se relacionam com o controle político e religioso que caracterizou o catolicismo tridentino e a Monarquia Hispânica na primeira metade do século XVII. Paralelamente à autobiografia de Pasamonte, a fim de reforçar a linha argumentativa mais ampla que conduz este trabalho, também faremos uma análise histórica de trechos do capítulo XXII do primeiro volume de Dom Quixote, de 1605, por haver neste capítulo a apresentação de um personagem chamado Ginés de Pasamonte, o qual pode ser entendido como uma leitura literária da figura do soldado Jerónimo de Pasamonte, realizada a partir da ótica de Miguel de Cervantes. Servindo-nos de respaldo historiográfico pertinente aos temas abordados, e fazendo uso de metodologia que toma por base a noção de história-problema, pretendemos demonstrar que a vida do soldado Pasamonte e o capítulo XXII de Dom Quixote são expressões de um mundo marcado pelo controle imperial exercido por intermédio de aparatos burocráticos, no que diz respeito à Monarquia Hispânica, e pelo controle das consciências, no âmbito do catolicismo tridentino.

Palavras-chave: autobiografias, catolicismo tridentino, disciplinamento social, Dom Quixote, Ginés de Pasamonte. 


\section{artigos}

\section{Erick Caixeta Carvalho}

\section{Introdução}

Em princípios de 1605, um soldado aragonês chamado Jerónimo de Pasamonte concluiu em Cápua, na península itálica, uma obra em que narrou sua vida, que posteriormente ficou conhecida como Vida y trabajos de Jerónimo de Pasamonte. Neste artigo, nos propomos a realizar uma análise histórica de alguns pontos dessa obra, enxergando-a como um documento que, além de nos oferecer a possibilidade de tomar conhecimento das memórias de um desconhecido soldado escritor do século XVII, nos permite compreender aspectos importantes da sociedade na qual este sujeito histórico viveu, partindo de seu olhar sobre seu mundo.

A vida de Jerónimo de Pasamonte já foi objeto de investigação de alguns estudiosos da obra de Miguel de Cervantes, dentre os quais cabe destacar Martín de Riquer, que publicou em 1988 o livro intitulado Cervantes, Passamonte y Avellaneda. A tese central de Riquer, compartilhada por estudiosos como Alfonso Martín Jiménez (2001) e Juan Antonio Frago Garcia (2005), é a de que Jerónimo de Pasamonte, que possivelmente conheceu Cervantes quando ambos eram soldados no início da década de 1570, foi o autor da obra que ficou conhecida como Quixote de Avellaneda, ou Quixote Apócrifo, publicada pela primeira vez em 1614, a qual teria impulsionado uma resposta de Cervantes com a publicação, no ano seguinte, do segundo volume de Dom Quixote. Independentemente da aprovação ou das críticas que esta tese suscitou no campo de estudos cervantistas, um ponto enfatizado por Ricoeur no segundo capítulo de sua obra (RIQUER, 1988) tornou-se bastante aceito entre os estudiosos do tema: o personagem Ginés de Pasamonte, apresentado no capítulo XXII do primeiro volume de Dom Quixote, possui estreitas relações com o soldado Jerónimo de Pasamonte, o qual teria servido de inspiração para Cervantes na 


\section{Controlar as vidas na Monarquia Católica}

construção de seu personagem. Não temos a pretensão, no presente trabalho, de nos aprofundarmos neste tema que já foi amplamente abordado por respeitados estudiosos cervantistas. No entanto, introduzimos aqui esta discussão para que, a partir de uma análise histórica do capítulo XXII do primeiro volume de Dom Quixote, realizada paralelamente à análise da vida de Jerónimo de Pasamonte, possamos levantar mais adiante questões e interpretações que nos permitam pensar aspectos da cultura escrita relacionada aos aparatos burocráticos da Monarquia Hispânica, bem como do disciplinamento social que caracterizou o catolicismo tridentino e o Estado Moderno em suas diversas formas de controle sobre os indivíduos.

Ainda de forma introdutória, cabe ressaltar algumas considerações teóricas e metodológicas que norteiam este trabalho. Consideramos as memórias de Pasamonte como uma visão parcial e monumentalizada da realidade, socialmente construída, pois como afirma Maurice Halbwachs, "cada memória individual é um ponto de vista sobre a memória coletiva" (HALBWACHS, 1990, p. 51). Não nos interessa aqui desvendar se o que o soldado escreve a respeito da Batalha de Lepanto (PASAMONTE, 2015, p. 147), por exemplo, aconteceu ou não da maneira como ele narrou. As memórias de Pasamonte, desse modo, enquanto apropriações do passado, não são feitas de forma neutra, mas a partir de interesses, conscientes ou não, próprios do tempo presente do escritor que narra o passado (LE GOFF, 1990, p. 477). Assim, a obra de Jerónimo de Pasamonte, enquanto documento e monumento, não pode falar por si própria a respeito do passado, e por esta razão precisamos interpretá-la de acordo com problemas que se colocam com base em nossas escolhas do presente. Seguindo uma visão de análise historiográfica, neste trabalho partiremos de questionamentos sobre as relações entre a escrita de si e o controle social, por parte dos poderes políticos e religiosos, que caracterizaram a 


\section{artigos}

\section{Erick Caixeta Carvalho}

Idade Moderna e que, apesar das enormes transformações históricas dos últimos séculos, ainda se manifestam em certos aspectos de nossa sociedade contemporânea.

\section{A escrita autobiográfica na Europa Moderna}

Ao longo da primeira metade do século XVII, num período correspondente ao chamado Século de Ouro Espanhol, diversos soldados escreveram vidas onde narraram suas trajetórias pessoais. O historiador Thomas Calvo, em sua obra intitulada Espadas y plumas en la Monarquía hispana: Alonso de Contreras y otras Vidas de soldados (1600-1650), publicada em 2019, apresenta um número de sete vidas de soldados do Século de Ouro que conhecemos atualmente (CALVO, 2019, p. 38). No entanto, não foram apenas soldados que se debruçaram neste empreendimento de escrita autobiográfica na Idade Moderna. Como James S. Amelang demonstrou em sua obra El vuelo de Ícaro: La autobiografía popular en la Europa Moderna, artesãos e grupos sociais que o autor denomina como "escritores populares urbanos" (AMELANG, 2003, p. 16) também escreveram textos que contém características autobiográficas.

É importante destacar, porém, que a utilização do termo "autobiografia" para tratar de textos dos séculos XVI e XVII pode suscitar polêmicas, já que este termo não era utilizado antes do final do século XVIII, e os debates acadêmicos sobre a origem do gênero autobiográfico apresentam perspectivas divergentes. De acordo com Philippe Lejeune, que em 1975 publicou a obra Le Pacte autobiographique, fundamental nos estudos do tema, seria possível definir uma autobiografia como sendo uma "narrativa retrospectiva em prosa que uma pessoa real faz de sua própria existência, quando focaliza sua história individual, em particular a história de sua 


\section{artigos}

\section{Controlar as vidas na Monarquia Católica}

personalidade" (LEJEUNE, 2008, p. 14). Por outro lado, Margarita Levisi, em sua obra publicada em 1984 sob o título Autobiografías del Siglo de Oro: Jerónimo de Pasamonte, Alonso de Contreras, Miguel de Castro, problematiza a conceituação de autobiografia proposta por Lejeune ao afirmar que esta parte das Confissões de Rousseau, o que dificultaria a aplicação do termo "aos textos de autores anteriores a este, que sem dúvidas escreveram acerca de si mesmos" (LEVISI, 1984, p. 16, tradução própria) ${ }^{1}$ Como o título da obra citada sugere, a autora considera as vidas de soldados do Século de Ouro, inclusive a de Pasamonte, como autobiografias. Levisi não é a única que assim procede. Sean Gullickson, em sua tese de doutorado defendida em 2015 na Universidade de Wisconsin-Madison, intitulada The Inner and Imagined Demons of Jerónimo de Pasamonte: Witchcraft, Psychology and Early Modern Autobiography, dedica o primeiro capítulo desta para tratar da autobiografia na Espanha moderna e, especialmente, da vida de Pasamonte, que o autor também considera como uma autobiografia. O historiador Antonio Castillo Gómez, por sua vez, embora julgue pertinente utilizar o termo "autobiografia" para tratar de diversos escritos dos séculos $\mathrm{XVI}$ e XVII, faz a seguinte ressalva, com a qual estamos de acordo neste trabalho: "No caso da primeira Idade Moderna, outrossim, é importante insistir na indefinição do gênero autobiográfico ou, em se preferindo, na pluralidade de escritos que se podem juntar sob tal categoria" (CASTILLO GÓMEZ, 2014, p. 168).

Tendo em vista tais ponderações, pode-se dizer que são diversas as razões que potencializaram a escrita de vidas com conteúdos autobiográficos na primeira Idade Moderna. De acordo com Thomas Calvo, "na primeira metade do século XVI se unem três fenômenos que vão potencializar os movimentos da alma ou os relatos das vidas"

\footnotetext{
${ }^{1}$ No original: "a los textos de autores anteriores a éste, que sin duda escribieron acerca de sí mismos".
} 
Erick Caixeta Carvalho

(CALVO, 2019, p. 24, tradução própria)2. O primeiro seria o humanismo, com "a figura única do indivíduo e sua valoração" (CALVO, 2019, p. 24, tradução própria) ${ }^{3}$. O segundo, a descoberta da América pelos europeus e o descobrimento do outro, "com todas as interrogações que nascem então sobre a natureza humana" (CALVO, 2019, p. 24, tradução própria) $)^{4}$. Por fim, o terceiro fenômeno elencado pelo autor seria a amplificação da relação com a divindade, resultado das reformas religiosas, tanto no âmbito protestante, quanto no católico. Segue-se a este período o que Calvo chama de século das introspecções, que corresponderia, grosso modo, ao intervalo entre os anos de 1580 a 1670. Estes seriam tempos marcados por dúvidas políticas e religiosas, mas que também ultrapassavam os questionamentos sobre o coletivo e envolviam aspectos introspectivos dos indivíduos (CALVO, 2019, p. 25). Os Ensaios de Montaigne, publicados pela primeira vez em 1580, podem ser vistos como marco inicial deste período, embora a Vida de santa Teresa de Jesus já demonstrasse traços da interioridade típica desta época. Sobre a data de 1670 como fechamento para este século das introspecções, as razões para esta escolha são explicadas por Calvo da seguinte maneira:

[...] a busca de verdade que acompanha o maneirismo favorecera o fogo interior do conhecimento de si mesmo, enquanto a claridade e extroversão do Barroco ou o rigor do classicismo francês o opacaram, até que, como outro fênix, renascera com as primícias do Romantismo e um personagem como Jean-Jacques Rousseau (CALVO, 2019, p. 25, tradução própria) ${ }^{5}$.

\footnotetext{
${ }^{2}$ No original: "En la primera mitad del siglo xvi, se unen tres fenómenos que van a potenciar los movimientos del alma o los relatos de las vidas".

${ }^{3}$ No original: "la figura única del individuo y su valoración".

${ }^{4}$ No original: "con todas las interrogaciones que nacen entonces sobre la naturaleza humana".

${ }^{5}$ No original: " [...] la búsqueda de verdad que acompaña al maneirismo favoreciera el fuego interior del conocimiento de sí mismo y la claridad y extraversión del Barroco o el rigor del clasicismo francés lo opacaran, hasta que, como otro fénix, renaciera con las primicias del Romanticismo y un personaje como Jean-Jacques Rousseau".
} 


\section{artigos}

\section{Controlar as vidas na Monarquia Católica}

Além das observações feitas por Thomas Calvo acerca da introspecção na Europa Moderna, no caso da escrita de vidas por parte de soldados da Monarquia Hispânica é possível destacar também o papel da burocracia imperial e da confissão, sendo este último ponto também observado por Calvo em sua obra já citada (CALVO, 2019, p. 30), como fatores propulsores da escrita destes relatos autobiográficos, tema que ainda retomaremos e desenvolveremos neste trabalho.

\section{A vida de Jerónimo de Pasamonte}

Jerónimo de Pasamonte, de acordo com Martín de Riquer, teve seu registro de batismo registrado na vila de Ibdes, próxima de Calatayud, em abril de 1553 (RIQUER, 1988, p. 13). Em sua obra autobiográfica, conhecida atualmente como Vida y trabajos de Jerónimo de Pasamonte, o autor narra memórias que tratam de um período que vai de sua infância até a época em que ele se encontra como um residente do Reino de Nápoles, em princípios do século XVII. De acordo com o que Pasamonte afirma nas dedicatórias de sua Vida, concluídas em janeiro de 1605, sua obra teria sido acusada como "livro de heresias" no arcebispado de Nápoles, onde teria ficado retida por quatro meses. Após este intervalo de tempo, o autor afirma que a obra foi devolvida a ele com uma licença para que pudesse ser impressa, o que ele afirma não ser sua intenção (PASAMONTE, 2015, p. 133).

O único manuscrito conhecido atualmente de Vida y trabajos se encontra na Biblioteca Nacional de Nápoles Vittorio Emanuele III, onde já estava conservado ao menos desde o século XIX, conforme podemos constatar por menção feita ao manuscrito de Pasamonte em uma obra de Alfonso Miola, bibliotecário da referida biblioteca (MIOLA, 1895, p. 69). No entanto, de acordo com o que o próprio Pasamonte afirma, o manuscrito em questão se trata de uma cópia de um manuscrito 


\section{artigos}

\section{Erick Caixeta Carvalho}

preexistente que fora encomendada pelo autor (PASAMONTE, 2015, p. 281). Não temos notícias do que ocorreu com o manuscrito no período correspondente ao intervalo entre a sua finalização, em 1605, e o ano de 1877, quando o erudito espanhol Marcelino Menéndez y Pelayo teria tido contato com ele em uma viagem à Nápoles (MENÉNDEZ Y PELAYO, 1915, p. 27).

A primeira versão impressa da vida de Pasamonte foi publicada por R. FoulchéDelbosc na Revue Hispanique, em 1922 (RIQUER, 1988, p. 11). É importante ressaltar que o manuscrito conservado na Biblioteca Nacional Nápoles não tem título próprio, o que levou Foulché-Delbosc a intitular a obra como Vida y trabajos de Gerónimo de Passamonte, com base no que Pasamonte diz em sua segunda dedicatória: "Todos mis trabajos y mi vida está aquí escrita" (PASAMONTE, 2015, p. 136) e no parágrafo preliminar da obra: "[...] escribo mi vida y trabajos desde mi infancia" (PASAMONTE, 2015, p. 139). O título dado por Foulché-Delbosc, com uma posterior atualização do nome do autor para Jerónimo de Pasamonte, passou a ser utilizado pela maioria dos estudiosos que se dedicaram a analisar este documento a partir de então, e por esta razão também o adotamos. No presente trabalho, utilizamos a edição impressa da autobiografia de Pasamonte organizada por José Ángel Sánchez Ibáñez e por Alfonso Martín Jiménez, publicada no ano de 2015.

Em sua obra, Pasamonte narra sua vida concedendo ênfase especial a dois pontos que norteiam toda a narrativa. O primeiro diz respeito aos sofrimentos enfrentados pelo autor e pela cristandade, que seriam causados por pessoas associadas a seres demoníacos, e principalmente por mulheres que Pasamonte considera como bruxas (PASAMONTE, 2015, p. 256). O segundo se refere aos livramentos divinos que desde a infância teriam salvado Pasamonte dos sofrimentos e dos ataques diabólicos, sendo estes livramentos a base que o soldado utiliza para 


\section{artigos}

\section{Controlar as vidas na Monarquia Católica}

propor resoluções para os problemas que ele associa ao que nomeia como "a ruína do mundo antes do tempo" (PASAMONTE, 2015, p. 274, tradução própria) ${ }^{6}$ e "a ruína de toda a cristandade" (PASAMONTE, 2015, pp. 136 e 279, tradução própria)

Apresentando-se como um cristão velho, cujos antepassados teriam servido ao rei católico Fernando de Aragão (PASAMONTE, 2015, p. 143), nos primeiros capítulos da obra Pasamonte narra diversos sofrimentos que enfrentou até os seus dez anos de idade: uma queda que quase o matou, um afogamento, a morte de sua mãe e de sua avó, além de diversas enfermidades graves (PASAMONTE, 2015, p. 140). Quando tinha aproximadamente dez anos, seu pai também morre, e então ele passa a residir primeiramente com seus tios Pedro Luzón e María de Pasamonte, depois com o bispo de Sória e, a seguir, com um médico que vivia numa casa onde um trasgo assombrava Pasamonte depois do anoitecer, o que o deixou doente e o teria levado à morte, se não fosse o livramento divino realizado por meio dos sacramentos da confissão e da eucaristia (PASAMONTE, 2015, p. 141).

Após uma tentativa frustrada de se tornar um clérigo (PASAMONTE, 2015, p. 142), intento que Pasamonte continuaria buscando por toda sua vida, aos dezoito anos ele se torna um soldado sob o comando de Dom Juan de Áustria (PASAMONTE, 2015, p. 143), participando das batalhas de Lepanto, em 1571, Navarino, em 1572, Túnez em 1573, e Goleta, em 1574, sendo que nesta última ele é capturado e passa a viver como um cativo. Após passar quase dezoito anos nesta condição, residindo em diversas cidades do Império Otomano e tentando por três vezes organizar fracassados planos de fuga, ele finalmente consegue sua liberdade, que é obtida por meio de um resgate.

\footnotetext{
${ }^{6}$ No original: "la ruina del mundo antes del tiempo".

7 No original: "la ruina de toda la cristiandad".
} 


\section{artigos}

\section{Erick Caixeta Carvalho}

Ao obter sua liberdade, Pasamonte chega a Nápoles em 1592, e em seguida percorre diversas cidades da Itália, antes de partir rumo à Espanha no ano de 1593. Em Zaragoza, recebe a notícia de que seu irmão mais velho, Esteban de Pasamonte, havia falecido. Tal notícia o deixa transtornado. Assim, o capítulo 38 da obra é concluído da seguinte maneira: "[...] se temos escritos muitos trabalhos, outros maiores e de nova impressão se haverão de escrever, e Deus quer algo deste miserável!" (PASAMONTE, 2015, p. 203, tradução própria) ${ }^{8}$.

Conforme José Ángel Sánchez Ibáñez e Alfonso Martín Jiménez observam em nota de rodapé na página 203 da edição de Vida y trabajos que utilizamos, no final do capítulo 38 Pasamonte estaria concluindo o que podemos considerar como a primeira parte de sua autobiografia, pois nos capítulos seguintes Pasamonte indica que o manuscrito de sua vida já estava sendo lido por algumas pessoas, prática comum na Península Ibérica desta época, conforme demonstra o historiador espanhol Fernando Bouza Alvarez em sua obra Corre manuscrito: Una historia cultural del Siglo de Oro, publicada em 2001. Ou seja, possivelmente Pasamonte escreveu sua obra ao longo de vários anos entre o início da década de 1590 e o ano de 1605, quando finalmente são concluídas as dedicatórias do manuscrito que atualmente se encontra na Biblioteca Nacional de Nápoles.

Nos capítulos que se seguem ao trigésimo oitavo, Pasamonte narra diversos outros sofrimentos e livramentos divinos que teriam ocorrido enquanto vivia na Espanha, em meados dos anos 1590, e depois, a partir do fim desta década, quando volta a atuar como soldado no Reino de Nápoles, onde se casa e tem filhos. Entretanto, passa a sofrer de uma mania persecutória, acreditando que é vítima de

\footnotetext{
${ }^{8}$ No original: "[...] si habemos escrito mucho trabajos, otros maiores y de nueva impresión se habrán de escribir, y Dios algo quiere desde miserable!"
} 


\section{artigos}

\section{Controlar as vidas na Monarquia Católica}

diversos feitiços e envenenamentos, inclusive por parte de seus sogros (PASAMONTE, 2015, p. 255), além de ser perturbado com visões diabólicas (PASAMONTE, 2015, p. 224). Nos capítulos finais de sua autobiografia, Pasamonte aparenta viver uma vida de intensa disciplina religiosa para escapar das feitiçarias e ciladas diabólicas das quais ele se entende como vítima, juntamente com a cristandade.

\section{O Pasamonte de Cervantes}

No capítulo XXII do primeiro volume de Dom Quixote é narrado o encontro do protagonista e de seu escudeiro, Sancho Pança, com "uns doze homens a pé, engranzados como contas numa grande cadeia de ferro pelos pescoços, e todos algemados" (CERVANTES, 1981, p. 121). Nas palavras de Sancho Pança, estes homens, que estavam acompanhados por soldados, eram "galeotes, gente forçada da parte de El-Rei, para ir servir nas galés" (CERVANTES, 1981, p. 121). Dom Quixote, ao ver a condição miserável dos prisioneiros, decidiu libertá-los, já que entendia ser este o dever de um cavaleiro andante. Antes, no entanto, passou a perguntar aos condenados quem eles eram e o que os havia levado àquela condição. Dentre os galeotes, um deles ocupa papel de destaque no capítulo, e é descrito por um guarda como "o famoso Ginés de Passamonte" (CERVANTES, 1981, p. 124). Ao fazer sua própria apresentação, ele diz: “sou Ginés de Passamonte; a minha vida está escrita por estes cinco dedos" (CERVANTES, 1981, p. 124). O comissário responsável por aqueles homens ainda acrescenta: “é verdade [...] a sua história escreveu-a ele próprio; é obra a que nada falta" (CERVANTES, 1981, p. 124). A seguir, Cervantes descreve um diálogo bastante pertinente para a análise histórica que buscamos desenvolver neste trabalho, portanto o reproduzimos adiante:

\section{— Pois tão bom é o livro? — disse D. Quixote.}




\section{artigos}

\section{Erick Caixeta Carvalho}

— Tão bom é - respondeu Ginés - que há de enterrar Lazarilho de Tormes, e quantos se têm escrito ou se possam escrever naquele gênero. O que sei dizer a você é que diz verdades tão curiosas e aprazíveis, que não pode haver mentiras que lhe cheguem.

— E como se intitula o livro? - perguntou D. Quixote.

— A vida de Ginés de Passamonte — respondeu ele em pessoa.

— E está acabado? — perguntou D. Quixote.

- Como pode estar acabado - disse ele - se ainda a vida se me não acabou? O que está escrito é desde o meu nascimento até ao instante em que esta última vez me encaixaram nas galés. (CERVANTES, 1981, pp. 124 e 125)

Como já apontou Martín de Riquer, Miguel de Cervantes e Jerónimo de Pasamonte foram soldados nas mesmas galeras no princípio da década de 1570 e, de acordo com este autor, "é evidente, pois, que Pasamonte e Cervantes se conheceram" e "é certo que como soldados enquadrados nas mesmas unidades, tinham as mesmas informações, os mesmos interesses e as mesmas preocupações" (RIQUER, 1988, p. 23, tradução própria) ${ }^{9}$. Riquer também ressalta que existiram grandes possibilidades de que Cervantes e Pasamonte tenham se encontrado em Madrid entre 1594 e 1595, quando ambos estavam nesta cidade tratando de questões que envolviam uma possível presença de ambos em departamentos administrativos da corte (RIQUER, 1988, p. 41). Além disso, cabe lembrar que Pasamonte afirma que um manuscrito correspondente aos primeiros 38 capítulos de sua vida teria sido lido por diversas pessoas em meados da década de 1590 (PASAMONTE, 2015, pp. 205, 208 e 210). Assim sendo, e também pelo fato já apontado por Alfonso Martín Jiménez de que há diversas semelhanças entre o personagem Ginés de Pasamonte e o soldado

\footnotetext{
${ }^{9}$ No original: “Es de toda evidencia, pues, que Passamonte y Cervantes se conocieron [...] é cierto que como soldados encuadrados en las mismas unidades, tenían las mismas informaciones, los mismos afanes y las mismas preocupaciones".
} 


\section{artigos}

\section{Controlar as vidas na Monarquia Católica}

Jerónimo de Pasamonte (Martín, 2001, pp. 55-95), podemos concluir que há suficientes evidências para considerarmos o personagem Ginés de Pasamonte como uma criação literária que Cervantes elaborou a partir do soldado Jerónimo de Pasamonte e do que este escreveu em sua vida. Feita esta observação, realizaremos uma análise histórica conjunta do capítulo XXII de Dom Quixote e da obra Vida y trabajos de Jerónimo de Pasamonte.

\section{Do memorial de Pasamonte à sua autobiografia}

Sei apenas que, se eu fosse rei, me dispensaria de responder a tanta infinidade de memórias impertinentes, como os que todos os dias lhe dão; que um dos maiores trabalhos que os reis têm, entre outros muitos, é o de estarem obrigados a escutar a todos, e a todos responder; e assim não desejaria eu que coisas minhas o molestassem. (CERVANTES, 1981, p. 334)

Estas palavras que Dom Quixote dirige à sua ama se encontram no sexto capítulo do segundo volume da obra, de 1615. Cervantes conhecia muito bem o tema tratado neste trecho, pois ele próprio solicitará ao rei Felipe II, por meio de um memorial datado do dia 21 de maio de 1590 (CERVANTES, 1590, fólio 2), o cargo de governador de Soconusco, ou o de corregedor na cidade de La Paz, ou ainda o de contador no Novo Reino de Granada ou na contadoria de galeras de Cartagena das Índias (CERVANTES, 1590, fólio 1). Para embasar sua solicitação, Cervantes expõe seus méritos através da descrição de seus serviços prestados enquanto soldado.

Nas palavras de John H. Elliott, ao longo do século XVI o Império Espanhol “deu lugar à larga proliferação inevitável de papéis e funcionários" (ELLIOTT, 2007, p. 37, tradução própria) ${ }^{10}$. O historiador H. R. Trevor-Roper, também tratando do Estado Moderno no século XVI, chamado por ele de "Estado da Renascença", afirma que este

\footnotetext{
${ }^{10}$ No original: “[...] dio lugar a la larga proliferación inevitable de papel y funcionários”.
} 


\section{artigos}

\section{Erick Caixeta Carvalho}

consistia "numa burocracia em contínua expansão" (TREVOR-ROPER, 1981, p. 58). Neste contexto é que se proliferaram na Monarquia Hispânica os memoriais escritos por soldados que desejavam obter recompensas por seus méritos e serviços prestados à Coroa, como já constatamos no caso do memorial de Cervantes.

Jerónimo de Pasamonte, conforme ele próprio indica, começou a escrever sua vida com a finalidade de apresentá-la como um memorial ao rei para a obtenção de recompensas por seus tantos sofrimentos e trabalhos realizados em nome do soberano. No capítulo 40 de sua vida, Pasamonte afirma que, quando estava em Madrid, em meados da década de 1590, "se deu memorial a Sua Majestade e saiu remetido a Francisco Idiáquez, a quem se deram meus papéis, que eram todos os trabalhos que atrás estão escritos" (PASAMONTE, 2015, p. 205) ${ }^{11}$. Os papéis com os "trabalhos que atrás estão escritos" se referem à primeira parte da obra de Pasamonte, ou seja, os capítulos que narram a trajetória de sofrimentos que Pasamonte teria enfrentado desde a sua infância, passando pelos seus tempos de soldado e, depois, pelos vários anos em que viveu como um cativo no Império Otomano.

Pasamonte não foi o único soldado que antes de escrever uma vida com características autobiográficas foi um escritor de memoriais, onde eram descritos feitos pessoais que tornavam o soldado digno de ter seu pedido de mercê contemplado pelo rei. O soldado Miguel de Castro, autor de uma autobiografia conhecida como Vida del soldado español Miguel de Castro, também afirma ter escrito memoriais (CASTRO, 1900, p. 204 e 207). Alonso de Contreras, que escreveu a mais famosa dentre as autobiografias de soldados do Século de Ouro Espanhol, intitulada

\footnotetext{
${ }^{11}$ No original: "se dio memorial a Su Majestad y salió remetido a Francisco Idiáquez, a quien se dieron mis papeles, que eran todos los trabajos que atrás están escritos".
} 


\section{artigos}

\section{Controlar as vidas na Monarquia Católica}

Discurso de mi Vida, em diversos momentos afirma ter escrito memoriais (CONTRERAS, 2005, pp. 11, 56, 67, 93, 128), como podemos constatar no sexto capítulo de sua obra autobiográfica: “Dei meu memorial no Conselho de Guerra pedindo que me aprovassem, e em consideração de meus poucos serviços fui aprovado" (CONTRERAS, 2005, p. 56, tradução própria) $)^{12}$.

Assim, a necessidade por parte dos soldados espanhóis de redigirem memoriais, nos quais deveriam escrever acerca de si próprios, por razões relacionadas ao controle burocrático da Monarquia Hispânica, foi um fator importante para a proliferação de autobiografias de soldados no Século de Ouro Espanhol. António Castillo Gómez, inclusive, ao tratar das autobiografias de soldados neste mesmo período, percebe a similaridade entre estas e os memorias de serviços, afirmando que "o principal conteúdo de seus escritos de vida é a exposição e argumentação dos méritos colhidos, como se se tratasse de uma folha de serviços visando uma promoção na carreira militar" (CASTILLO GÓMEZ, 2014, p. 168).

Tendo em vista que nestes memoriais os soldados deveriam colocar por escrito os aspectos de suas trajetórias pessoais que os tornavam merecedores de uma mercê, podemos argumentar que Pasamonte começou a escrever seus sofrimentos e serviços prestados à Coroa a fim de que pudesse ser agraciado com alguma recompensa "por todos os trabalhos que atrás estão escritos", como ele se refere ao conteúdo de seu memorial. No entanto, em consonância com o que dizia o personagem Ginés, o soldado Pasamonte não se contentou em dar por acabada a sua vida apenas com o conteúdo de seu memorial, onde narrava sua vida desde a sua infância até o momento em que remou nas galés, quando cativo no Império

\footnotetext{
12 No original: “Di mi memorial en el Consejo de Guerra pidiendo me aprobasen, y en consideración de mis pocos servicios fui aprobado"
} 


\section{artigos}

\section{Erick Caixeta Carvalho}

Otomano. Assim, embora Cervantes possivelmente conhecesse (por contato direto ou indireto) apenas a primeira parte da vida de Pasamonte, ou seja, o memorial endereçado a Felipe II que possivelmente circulou em Madrid nos últimos anos do reinado deste monarca, ele também deveria estar ciente das pretensões que Pasamonte possuía de não dar por concluída a escrita de sua vida até o momento em que remará nas galeras no Império Otomano, já que o personagem Ginés de Pasamonte responde a Dom Quixote que o livro onde narra sua vida desde o nascimento até a última vez que havia remado nas galés ainda não poderia estar acabado, pois o autor da vida ainda estava vivo (CERVANTES, 1981, p. 125). Assim, Cervantes utiliza da comicidade característica da obra Dom Quixote para satirizar, através de um personagem caricato inspirado em Jerónimo de Pasamonte, o desejo pouco usual deste soldado anunciado na conclusão da primeira parte de sua autobiografia: “[...] se temos escritos muitos trabalhos, outros maiores e de nova impressão se haverão de escrever, e Deus quer algo desde miserável!" (PASAMONTE, 2015, p. 203, tradução própria) ${ }^{13}$.

Cabe lembrar que, dentre as sete autobiografias de soldados do Século de Ouro que conhecemos atualmente (CALVO, 2019, p. 38), a de Jerónimo de Pasamonte é provavelmente a mais antiga. Ou seja, possivelmente Cervantes teria considerado como algo incomum e cômico o fato de que um soldado como Pasamonte desejasse escrever sua própria vida, de modo a ultrapassar as características práticas e comuns dos memoriais de serviços. O gênero vida, já conhecido na antiguidade clássica e bastante comum na Idade Média, especialmente pelas vidas de santos (BAÑOS VALLEJO, 2003), não tinha como característica comum, retomando a definição de autobiografia feita por Lejeune, uma “narrativa retrospectiva em prosa que uma

\footnotetext{
${ }^{13}$ No original: "[...] si habemos escrito mucho trabajos, otros maiores y de nueva impresión se habrán de escribir, y Dios algo quiere desde miserable!"
} 


\section{artigos}

\section{Controlar as vidas na Monarquia Católica}

pessoa real faz de sua própria existência" (LEJEUNE, 2008, p. 14). Cícero, cuja presença entre os letrados da Europa nos séculos XVI e XVII era notável, tendo inclusive seus textos utilizados nos colégios jesuítas para a alfabetização das crianças neste período (CERQUEIRA, 2017, p. 17), fez a seguinte afirmação em uma carta ao historiador Lucio Luceio, ao tratar daqueles que escrevem seus próprios feitos:

Há os seguintes problemas nesse tipo de escrito: é forçoso que escrevam a respeito de si mesmos com muito pudor, se houver algum motivo de elogio, e que façam omissões, se houver algo censurável. Soma-se ainda o fato de que é menor a credibilidade, menor a autoridade, e que muitos, enfim, criticam essa prática, afirmando que têm maior pudor os arautos dos jogos gímnicos, pois coroam os demais vencedores e anunciam os nomes deles em voz alta, mas quando eles próprios são premiados com a coroa, convidam outro arauto antes do término dos jogos, para não terem de anunciar sua vitória com a própria voz (CÍCERO, 2019, p. 102).

Como já apresentamos anteriormente, Pasamonte não foi o único soldado a se aventurar na empreitada de escrever sua própria vida no século XVII, mas ainda assim, este tipo de escrita poderia soar como algo reprovável para Cervantes e para outros que tendiam a seguir uma opinião como a de Cícero. Cabe ressaltar que Cervantes compara a vida de Pasamonte, que pretendia narrar uma história verdadeira sobre si, com a vida de Lazarillo de Tormes, o que nos indica que Cervantes também retrata a escrita autobiográfica de Pasamonte como um caso cômico, ridículo e exageradamente pretensioso. No entanto, embora tal diálogo seja uma invenção literária de Cervantes, ele já se tornara verossímil para a realidade da Monarquia Hispânica nos primeiros anos do século XVII, de tal modo que os soldados escritores de suas próprias vidas se proliferaram neste período, como podemos 


\section{Erick Caixeta Carvalho}

constatar por meio das diversas autobiografias de soldados do Século de Ouro que conhecemos atualmente.

Concluímos, portanto, que a proliferação de papéis ocasionada pela burocracia da Monarquia Hispânica, vinculada à necessidade de administrar e manter o controle das vidas dos súditos num império multicontinental que já se encontrava em crise desde o final do século XVI, foi um dos fatores, embora não seja o único (CALVO, 2019, p. 24), que tornou possível a existência da autobiografia de Jerónimo de Pasamonte e, ao mesmo tempo, possibilitou a verossimilhança presente no diálogo entre Ginés de Pasamonte e Dom Quixote.

\section{Controlar as vidas na Monarquia Católica: a autobiografia de Pasamonte e os Tribunais da Consciência}

O historiador italiano Adriano Prosperi, em sua obra Tribunais da Consciência: Inquisidores, Confessores, Missionários, considera a Idade Moderna como caracterizada por um processo de disciplinamento social ${ }^{14}$ que teve como uma de suas principais características o que o autor chama de "controle das consciências", com base numa célebre passagem de um texto de Tommaso Campanella, do ano 1604: "a lei de Cristo tem os tribunais da consciência perante os quais cada um deve penitenciar-se das culpas, fazendo em si justiça voluntária" (CAMPANELLA, 2004 apud PROSPERI, 2013, p. 23). Prosperi, ao escrever sobre a Idade Moderna a partir das reformas religiosas do século XVI, faz a seguinte afirmação:

A imposição de uma disciplina social passou por seu arraigamento nas

\footnotetext{
${ }^{14}$ Como apontaremos mais adiante, os estudos de Michel Foucault estão entre os mais notáveis no que diz respeito ao tema do disciplinamento social na Idade Moderna. Até onde temos conhecimento, Adriano Prosperi, em sua obra Tribunais da Consciência, publicada nos anos 1990, não faz menções aos estudos de Foucault. Ainda assim, acreditamos que estes dois autores possuem pontos de convergência em suas análises, ainda que para o presente trabalho as análises de Prosperi dialoguem mais com nossos objetivos.
} 


\section{artigos}

\section{Controlar as vidas na Monarquia Católica}

consciências: considerando-o à distância de séculos, Karl Marx atribuiu a Lutero o mérito de ter "emancipado o corpo da cadeia, acorrentando o coração". Mas fora o católico Giovanni Botero a oferecer a mediação da Igreja ao poder político do estado-Leviatã que avançava, sustentando que somente a religião podia soldar nos corações o vínculo da obediência (PROSPERI, 2013, p. 45).

Assim, podemos afirmar que o controle político e administrativo exercido com o auxílio dos aparatos burocráticos da Monarquia Hispânica, que não por acaso também pode ser chamada de Monarquia Católica, não estava desvinculado do controle religioso que no catolicismo tridentino se manifestou como uma disciplina social arraigada nas consciências e que, de acordo com Prosperi, teria sido posta em prática a partir do uso de três aparatos institucionais da Igreja: a Inquisição, a confissão e as atividades missionárias. Ao tratar do catolicismo tridentino, Prosperi afirma:

\footnotetext{
Como disse o jesuíta Lainez no Concílio de Trento, estava em curso uma reforma do homem interior (reformatio interioris hominis) paralela àquela do homem exterior. E à reforma do homem interior foi dedicada uma farta literatura espiritual, na qual foram propostos remédios, sugestões, conselhos para tornar o homem virtuoso naquele que Lorenzo Scupoli denominou "combate espiritual" (PROSPERI, 2013, p. 486).
}

Como já aponta Castillo Gómez, a autobiografia de Jerónimo de Pasamonte possui características comuns com as chamadas "autobiografias espirituais", como a que escreveu a freira Ana de Jesus (CASTILLO GÓMEZ, 2014, p. 196). De acordo com Pasamonte, em sua dedicatória ao dominicano Jerónimo Javierre, que na ocasião acabara de se tornar confessor de Felipe III, a sua intenção ao escrever toda sua vida era a de demonstrar, através de suas experiências, quais eram as causas do que ele considerava como a ruína da cristandade, para que, assim, "se dê remédio a tantos danos como os existem entre católicos" (PASAMONTE, 2015, p. 136, tradução 


\section{artigos}

\section{Erick Caixeta Carvalho}

própria) ${ }^{15}$. De certo modo, podemos aproximar a autobiografia de Pasamonte, ao menos em seus capítulos finais, daquela "literatura espiritual", como é o caso do Livro da Vida de Santa Teresa, à qual Prosperi se refere, dedicada a oferecer "remédios, sugestões, conselhos para tornar o homem virtuoso naquele que Lorenzo Scupoli denominou 'combate espiritual'"' (PROSPERI, 2013, p. 486) ${ }^{16}$.

Como já mencionamos, a autobiografia de Pasamonte pode ser dividida em dois grandes blocos: os primeiros 38 capítulos foram escritos com características mais próximas às de um memorial de serviços, e é esta parte da vida de Pasamonte que circulou como manuscrito em Madrid na década de 1590, sendo esta primeira parte a que inspirou Cervantes no capítulo XXII de Dom Quixote. No entanto, como Cervantes parecia ter ciência, Pasamonte deu prosseguimento à escrita de sua vida, sendo que nos capítulos finais de sua obra, ele coloca ênfase menor nos feitos de sua vida externa, enquanto soldado, e se volta especialmente para sua vida interior e sua trajetória espiritual. Assim, Margarita Levisi chega a afirmar que Vida y trabajos de Jerónimo de Pasamonte

contém não uma, mas, de fato, duas autobiografias, diferenciadas pelo próprio Pasamonte: a primeira, na qual se dá conta dos feitos externos de sua vida, e a segunda - muito mais breve - que registra exclusivamente sua evolução espiritual, partindo - como no caso da história de sua trajetória externa - das recordações da infância distante (LEVISI, 1984, p. 34, tradução própria) ${ }^{17}$.

\footnotetext{
${ }^{15}$ No original: "se dé remedio a tantos daños como hay entre católicos".

${ }^{16}$ Ainda que não tenhamos condições, neste trabalho, de tratar a respeito relações entre as vidas de soldados e a literatura espiritual desta mesma época, fazemos questão de mencionar a existência de semelhanças entre elas, sendo que até o famoso fundador da Companhia de Jesus, Inácio de Loyola, por exemplo, reuniu em si aspectos destes dois grupos.

17 No original: "contiene no una, sino, en efecto, dos autobiografias, diferenciadas por el mismo Pasamonte: la primera, en la que se da cuenta de los hechos externos de su vida, y la segunda - mucho más breve - que consigna exclusivamente su evolución espiritual, partiendo - como en el caso de la historia de su trayectoria externa - de los recuerdos de la lejana infancia".
} 


\title{
Controlar as vidas na Monarquia Católica
}

Conforme também já discutimos anteriormente, podemos destacar dois temas que norteiam a obra de Pasamonte: os sofrimentos enfrentados por ele próprio e pela cristandade, e os livramentos divinos que acompanharam Pasamonte ao longo de toda a sua vida. Pasamonte acreditava, conforme fica evidente no capítulo 54, que todos os seus sofrimentos, bem como sua fidelidade e sua comunhão com a Igreja, legitimariam sua pretensão de oferecer um "remédio" para os problemas da cristandade. O capítulo 54 de Vida y trabajos começa com uma pergunta retórica, seguida de uma reflexão onde Pasamonte expõe o que legitimaria sua escrita:

\begin{abstract}
Dirá algum especulativo, e melhor sofístico: "O que se mete este soldado néscio, sem estudo, nestas disputas, pois a Igreja de Deus tem tantos doutores para defender suas causas?" A isso respondo que o haver derramado mais sangue que alguns em serviço de meu Deus, como se vê pelo escrito atrás, e haver pregado, com seu divino favor, sua santa fé em terra de inimigos da fé, e compadecer-me dos que meu Deus redimiu. Também dirá: “Não seria melhor a este soldado ter feito uma memoria de seus pecados, da própria idade que começou a escrever seus trabalhos, e fazer uma confissão geral deles, que the importaria mais?" A isso respondo que já o fiz duas vezes: uma em Espanha, quando vim da Turquia, com um padre que se chamava Contreras, da ordem de Santo Domingo em Calatayud; e outra fiz Nápoles. [...] E para que se veja que em soldados como eu tem Deus algum bom estilo por sua graça, quero contar minha vida espiritual como contei meus muitos trabalhos. (PASAMONTE, 2015, p. 257, tradução própria) ${ }^{18}$
\end{abstract}

\footnotetext{
18 No original: "Dirá algún especulativo, y mejor sofístico: “¿Quién le mete a este soldado necio sin estudio en estas disputas, pues la Iglesia de Dios tiene tantos doctores para defender sus causas?" A eso respondo que el haber derramado más sangre que algunos en servicio de mi Dios, como se ve por lo escrito atrás, y haber predicado, con su divino favor, su santa fe en tierra de enemigos de la fe, y compadecerme de los que mi Dios ha redimido.También dirá: “¿No le era mejor a este soldado haber hecho una memoria de sus pecados, de la propia edad que ha comenzado a escribir sus trabajos, y hacer una confesión general de ellos, que le importara más?" A eso respondo que 1 ya lo he hecho dos veces: uma en España, cuando vine de Turquía, con un padre que se llamaba Contreras, de la orden de Santo Domingo en Calatayud; y otra he hecho en Nápoles, a la persecución de mis suegros, que esperando que viniese el año santo me entretenía que viniese a Nápoles; y, no viniendo, hice la confesión general con fray Ambrosio Palomba, que agora es prior de Soma, de la religión de Santo Domingo, porque creí cierto morir de los venenos de mis suegros, si Dios no obrara con su divino favor. Y para que se vea que en soldados como yo tiene Dios algún buen estilo por su gracia, quiero contar mi vida espiritual como he contado mis muchos trabajos".
} 


\section{artigos}

\section{Erick Caixeta Carvalho}

A seguir, Pasamonte passa a narrar suas práticas de devoção religiosa, enfatizando um aspecto que, de acordo com Prosperi, seria um dos mais importantes mecanismos de controle sobre as consciências utilizado pelo catolicismo tridentino: a confissão. Em diversos momentos de sua vida, Pasamonte ressalta a importância da confissão e demonstra que confessa com frequência (PASAMONTE, 2015, pp. 141, $166,196,201,205,217,218,223,225,243,253,261)$. Ao tratar de suas práticas devocionais, ele afirma: “com a maior humildade e devoção que posso, digo a confissão geral e [...], acusando-me algum pecado, se o cometi depois que me confessei, com o propósito de confessá-lo ao confessor". (PASAMONTE, 2015, p. 261, tradução própria) ${ }^{19}$. Também podemos observar a importância da confissão para Pasamonte através de um diálogo entre ele e uma mourisca chamada Jerónima:

- Há pouco tempo me confessei [...] eu confesso o que me recordo e o que o confessor me pergunta.

Ela saltou e disse às outras:

- Não te disse eu que não deves confessar senão o que o confessor te pergunta?

Eu, então, me enojei e lhes disse as seis regras que frei Luis de Granada coloca, e que, calando um pecado por temor ou malícia, a confissão não é válida. A mourisca traidora se enojou muito porque eu a repreendi (PASAMONTE, 2015, p. 218, tradução própria) ${ }^{20}$.

\footnotetext{
19 No original: "con la más humildad y devoción que puedo, digo la confesión general y [...], acusandome algún pecado si lo he cometido después que me confesé, con propósito de confesallo al confesor".

${ }^{20}$ No original: "-Poco ha que me confesé [...] yo confieso lo que me acuerdo y lo que el confesor me pregunta.

Ella saltó y dijo a las otras:

-¿No te dije yo que no has de confesar sino lo que el confesor te pregunta?

Yo entonces me enojé y les dije las seis reglas que fray Luis de Granada pone 1, y que, callando un pecado por temor o malicia, la confesión no es válida. La morisca traidora se enojó mucho porque yo la reprehendí".
} 


\section{artigos}

\section{Controlar as vidas na Monarquia Católica}

Segundo Prosperi, “a confissão era, por convicção geral, a porta da conversão, isto é, a passagem essencial para a construção da identidade" (PROSPERI, 2013, p. 486). Pasamonte, enquanto católico profundamente fiel à Igreja, aprendera a examinar sua consciência interior e suas atitudes da vida exterior para que, assim, pudesse recordar seus pecados a fim de confessá-los. Cabe ainda ressaltar, com base no que já atestamos a partir dos trechos que abrem o capítulo 54 da autobiografia, que Pasamonte, cujo confessor é apresentado como um padre da Companhia de Jesus (PASAMONTE, 2015, p. 196), ordem religiosa, fundada por Inácio de Loyola, que exerceu grande protagonismo nas releituras do sacramento da confissão no contexto do catolicismo tridentino (PROSPERI, 2013, p. 484), afirma ter feito por duas vezes "confissões gerais" de todos seus pecados. De acordo com Prosperi,

na história da ordem fundada por Inácio, a proposta da confissão geral devia tornar-se uma das mais importantes: ela encarnava melhor do que qualquer outra prática devota o movimento que das profundezas da abjeção levava ao desejo de resgate, do conhecimento de si mesmo à vitória sobre os próprios instintos culpados - e portanto, do abismo do pecado à cúspide da perfeição (PROSPERI, 2013, p. 487).

Assim, não pensamos que seja apenas uma coincidência o fato de que uma autobiografia como a de Pasamonte viesse a ser escrita justamente numa época em que o exame das consciências era altamente estimulado pela Igreja, numa prática que instigava o "conhecimento de si mesmo", como um modo de afastar o pecado, a heresia e a desobediência, o que manteria sob o controle da Igreja as consciências dos fiéis numa época onde estava em marcha um rigoroso disciplinamento religioso e social.

\section{Conclusão}

Embora neste artigo tenhamos partido principalmente dos estudos do 


\section{artigos}

\section{Erick Caixeta Carvalho}

historiador Adriano Prosperi para tratar tema do disciplinamento social na modernidade, diversos outros intelectuais renomados, dentre os quais cabe destacar Michel Foucault, também trabalharam com essa temática, ainda que a partir de abordagens diversas. Foucault, por exemplo, atribui ao Estado Moderno "um papel de disciplinamento: ou seja, a um só tempo, de seleção, de homogeneização, de hierarquização, de centralização" (FOUCAULT, 2002, p. 222), o que também vai ao encontro do que buscamos argumentar neste trabalho.

Como procuramos demonstrar, as práticas de controle burocrático da Monarquia Hispânica, juntamente com as práticas de controle religioso do catolicismo tridentino, especialmente através do "conhecimento de si mesmo" instigado pela confissão, podem ser compreendidas como fatores que propiciaram um tipo de escrita autobiográfica por parte de soldados no Século de Ouro Espanhol, como foi o caso da obra Vida y trabajos de Jerónimo de Pasamonte. O aparecimento desse tipo de escrita, como apresentamos, foi notado por Cervantes, que no capítulo XXII de Dom Quixote fez uma comparação interessante entre a vida de Pasamonte, do personagem Ginés de Pasamonte, e a vida de Lazarillo de Tormes, publicada pela primeira vez na década de 1550. Assim, Cervantes aproveita justamente da novidade desse tipo de escrita para produzir efeitos cômicos a partir da apresentação de um homem de baixo estrato social que desejou escrever sua própria vida com base em "verdades tão curiosas e aprazíveis, que não pode haver mentiras que the cheguem" (CERVANTES, 1981, p. 124). 


\section{Fontes}

CASTRO, Miguel de. Vida del soldado español Miguel de Castro. Edição de Antonio Paz y Meliá. Madrid: Editora M. Murillo, 1900.

CERVANTES DE SAAVEDRA, Miguel de. Dom Quixote de la Mancha. Tradução dos Viscondes de Castilho e Azevedo; notas de José María Castro Calvo, traduzidas por Fernando Nuno Rodrigues. São Paulo: Abril Cultural, 1981.

- Memorial (al parecer de la letra de Cervantes) en la que expone sus méritos y servicios hechos en Italia, en la batalla de Lepanto y en otras partes, con motivo de solicitar la concesión de cualquiera de los cuatro puestos vacantes que expone: la contaduría del Nuevo Reino de Granada, la gobernación de Soconusco, la contaduría de las galeras de Cartagena de Indias, o el corregimiento de la ciudad de La Paz. Código de referência: ES.41091.AGI/29//PATRONATO,253,R.1. 1590. Disponível em: http://pares.mcu.es/ParesBusquedas20/catalogo/description/126853. Acesso em: 23 de julho de 2020.

CíCERO. Carta a Lúcio Lucrécio, Fam 5.12. Tradução de Adriano Scatolin. Juiz de Fora: RÓNAI - Revista de Estudos Clássicos e Tradutórios, V.7 N.2 - p. 92-106, 2019.

CONTRERAS, Alonso de. Discurso de mi vida desde que salí a servir al rey, de edad de catorce años, que fue en el año de 1597, hasta el fin del año de 1630, por primero de octubre, que comencé esta relación. Edição de Enrique Suárez Figaredo. Barcelona, 2005.

PASAMONTE, Jerónimo de. Vida y trabajos de Jerónimo de Pasamonte. Ed. de José Ángel Sánchez Ibáñez y Alfonso Martín Jiménez. Alicante: Biblioteca Virtual Miguel de Cervantes, 2015.

\section{Referências bibliográficas}

AMELANG James S. El vuelo de Ícaro: la autobiografía popular en la Europa Moderna. Madrid : Siglo XXI de España Editores, 2003.

BAÑOS VALLEJO, Fernando. Las Vidas de Santos en la Edad Media. Madrid: Ediciones del Laberinto, 2003.

BOUZA ÁLVAREZ, Fernando. Corre manuscrito. Una Historia cultural del siglo de oro. Madrid, Marcial Pons, 2001. 


\section{artigos}

\section{Erick Caixeta Carvalho}

CALVO, Thomas. Espadas y plumas en la Monarquía hispana: Alonso de Contreras y otras vidas de soldados (1600-1650). Madrid: Casa de Velázquez, 2019.

CASTILLO GÓMEZ, Antonio. Livros e leituras na Espanha do Século de Ouro. Tradução Claudio Giordano, 1ª Ed. Cotia, SP: Ateliê Editorial, 2014.

CERQUEIRA, André Sekkel. A donzela alada: reflexões sobre a retórica e história em Portugal no século XVII. 2017. Dissertação (Mestrado em História Social) - Faculdade de Filosofia, Letras e Ciências Humanas, Universidade de São Paulo, São Paulo, 2017. doi:10.11606/D.8.2017.tde-17072017-192645. Acesso em: 2020-08-05.

ELLIOTT, John. España y su mundo (1500-1700). Tradução de Ángel Rivero Rodríguez e Xavier Gil Pujol. Madrid: Editora Santillana, 2007.

FOUCAULT, Michel. Em Defesa da Sociedade: curso dado no collège de France (19751976). Tradução de Maria Emantina Galvão. São Paulo: Martins Fontes, 2002.

FRAGO GARCIA, Juan Antonio. El Quijote apócrifo y Pasamonte. Madrid: Editorial Gredos, 2005.

HALBWACHS, Maurice. A memória coletiva. São Paulo: Vértice, 1990.

GULLICKSON, Sean. The Inner and Imagined Demons of Jerónimo de Pasamonte: Witchcraft, Psychology and Early Modern Autobiography, 2015. Tese - Spanish Departament, Universidade de Wisconsin - Madison, Wisconsin, 2015.

LE GOFF, Jacques. História e memória. Tradução de Bernardo Leitão et al. Campinas: Editora da UNICAMP, 1990.

LEJEUNE, Philippe. O pacto autobiográfico: de Rousseau à Internet. Belo Horizonte: Editora UFMG, 2008.

LEVISI, Margarita. Autobiografías del Siglo de Oro: Jerónimo Pasamonte, Alonso de Contreras, Miguel de Castro. Madrid: Sociedad General Española de Librería, 1984.

MARTÍN JIMÉNEZ, Alfonso. El «Quijote» de Cervantes y el «Quijote» de Pasamonte: una imitación recíproca. La "Vida" de Pasamonte y "Avellaneda". Alcalá de Henares: Centro de Estudios Cervantinos, 2001.

MENÉNDEZ Y PELAYO, Marcelino. Orígenes de la novella, IV. Madrid: 1915.

MIOLA, Afonso. Notizie di Manoscritti Neolatini, Parte prima. Nápoles: Presso 


\section{artigos}

Controlar as vidas na Monarquia Católica

Federico Furchheim, $1895 . \quad$ Disponível em <
https://archive.org/details/notiziedimanoscr00mioluoft>. Acesso em 19/12/2016.

PROSPERI, Adriano. Tribunais da Consciência: Inquisidores, Confessores, Missionários. São Paulo, EDUSP, 2013.

RIQUER, Martín de. Cervantes, Passamonte y Avellaneda. Barcelona: Sirmio, 1988

TREVOR-ROPER, H. R. Religião, Reforma e transformação social. Lisboa: Presença, 1981. 